IOS Press

\title{
Editorial
}

\section{Introduction to the Special Issue}

\author{
Alan E. Singer and Pavel Castka
}

This special issue of HSM on corporate social responsibility (CSR) has benefited greatly from the support of Professor Prakash Sethi and Olga Emelianova of the International Center for Corporate Accountability in New York, who drew our attention to some of the papers that were presented at the ICCA June 2007 conference at Baruch College on "Globalization and the Good Corporation". The theme of that conference was "CSR and its economic, environmental and human rights implications". The resulting HSM collection, which combines papers from the NY conference with others submitted directly to the journal, highlights the role of HSM as a documenter of ideas applicable to and employed by international management; including ideas about ethics and business purposes. The accepted papers come from scholars in many countries: Japan, Korea, Turkey, Italy, Romania, Czech-Republic, New Zealand, UK and the USA. They take the form of CSRrelated case studies, surveys, policy advocacy and theoretical frameworks. It is quite apparent that CSR and HSM have become ubiquitous.

In the first paper, Tae Choi and Chiaki Nakano report that in Japan and Korea, interest in corporate social responsibility and business ethics has increased during the last decade. Japanese and Korean companies have made substantial progress in "establishing corporate ethics", whilst views about the basic meaning of ethics have not changed. Korean managers' views on ethics and its role in business are a mixture of Japanese and American elements. It thus seems that people from different cultures share essentially similar understandings about what it means to "act good" in the modern World (cf. [10], p. 44).

The question remains, however, as to whether and where human beings are acting better: that is, making moral progress. ${ }^{1}$ Japan and Korea are amongst

\footnotetext{
${ }^{1}$ For other recent perspectives on the question, see the special issue of the International Journal of Entrepreneurship \& Small Business 6(1) (2008) on "Entrepreneurship and Moral Progress".
}

the many countries where managerial "measures" have been taken; but it remains contested and unclear as to whether CSR-related business activities amount to an "evolution of moral consciousness in the executive suite" (cf. [1]). According to Choi and Nakano, contemporary Korean and Japanese managers tend to align themselves with their companies (compliance rather than ethics) ... and this tendency becomes increasingly pronounced the further one goes up the corporate ladder. In the past, according to Adam Smith (1776) business activities for the social good represented nothing more than affectations by merchants.

All the papers in the issue should be read with these ambiguities and contests in mind. The following two papers narrate case-studies of measurement and control systems for two ethically-infused aspects of business: Corporate Governance (CG) in Turkey and Intellectual Capital Reporting (i.e. Financial Accounting) in Italy. Serap Atakan, Zeynep Ozsoy and Beyza Oba (Bilgi University) report that the Istanbul Stock Exchange has devised a new corporate governance index that became operational in August 2007. They describe the implementation of the relevant business principles by a leading media-entertainment conglomerate: Dogan Yayın Holding (DYH).

While their case study sets out the processes adopted by $\mathrm{DYH}$, it also attempts to reveal the motives of DYH. In an industry that is inherently political, the process is reported to be successful from the perspective of stakeholders. Motives aside, the implementation of CG principles in this case led to an improvement of the corporate image and the gaining of prestige in the eyes of foreign institutional investors. ${ }^{2}$ The case writers con-

\footnotetext{
${ }^{2}$ It is perhaps also worth recalling that in the 1980s (the era of Competitive Strategy), Turkey was the host to innovative studies of the competitiveness of its manufacturing industry (e.g. [8]). Two decades later, academic and political concerns have shifted away from competition and towards good governance, or "Social Strat-
} 
sider that this helped to improve the overall investment environment in Turkey. Nonetheless, in reflecting upon the larger question of moral progress in business, it should not be forgotten that in Turkey, like several small advanced economies, the majority of listed companies are tightly held and are ultimately controlled by a small number of wealthy families through a complicated web of shareholdings.

Although the measurement and reporting of Intellectual Capital (IC) might seem at first to be un-related to CSR, there are many areas of overlap. Like CSR, the IC discourse is also highly politicized and contested. A view-from-the-left sees that the very language of "IC" constitutes an attempt to capture essentially human practices of knowledge production in dollar terms, trampling over intrinsic and expressive values. A contrasting view-from-the-right also reviles the concept of intellectual capital, this time because it is "a potential Trojan horse for those who want stakeholders, not stockholders to control our companies" (Rutledge 1997; cited in [7], p. 370).

Perhaps then the middle ground is the best place to be. The paper by Maria Chiucchi (University of the Marche, Ancona, Italy) occupies this territory on questions such as business motives and authenticity. According to Chiucchi, the processes that lead to the production of an IC statement in a company create "positive effects" on its reputation, as well as the company's capacity to communicate with stakeholders and "listen to their needs". The case of Aimag S.p.A., a multiutility Italian company, suggests that the IC reporting systems cannot be simply considered an accounting phenomenon. Rather, they promote managerial and cultural change within a company, especially with respect to stakeholder engagement. These systems require a high level of transparency (i.e. open books), enabling stakeholders to gain better understandings and increasing the level of trust. Accordingly, it is claimed in the paper that IC reporting constitutes "an evolution in accounting systems": one that improves the quality of stakeholder management and has positive (moral) effects.

The fourth paper in the issue, co-authored by one of the editors, offers a review and critical analysis of the recent Global ISO standards that relate to CSR. Pavel Castka (Canterbury, NZ) and Michaela Balzarova (Lincoln, NZ) ask whether certification per se enhances the uptake of CSR and especially whether or not

egy". This arguably reflects Knight's [4] postulate of an inverted-Uform relationship between intensity of competition and ethical behavior in business. such certification contributes to the actual improvement of social and environmental conditions. They offer some pragmatic arguments as to why standardsplus-certification are now seen as politically-correct: the "right" way to construct governance systems for the self-regulatory networks that now comprise the institutional expression of environmental concerns. First, ISO standards act as a valuable source of information that helps managers to address CSR issues. Secondly, as they put it: "the key word is 'certification' - otherwise (today's) managers do not seem to be interested".

The latter emphasis quickly strengthens the hand of the "skeptics". There are fundamental problems with this "correct" or "right" way, that first become apparent during the process of developing the standards. As has repeatedly occurred in CSR-relevant areas such as taxation, subsidies and intellectual property regimes, these processes typically safeguard the interests of directly-participating parties in ways that are arguably at the expense of the overall public interest. In the case of ISO 14001 (an environmental standard) negotiations do indeed seem to have been dominated by the industries involved. Then, after the "negotiated" standards and their indicators are put in place, most corporate managers (including those working in the "certification industry" itself) typically become far more concerned with generating the right indicators (the numbers) than with actually doing a good job.

To give an example, King and Lennox [2] observed that participants in a "Responsible Care" program for the chemical industry were precisely the firms that had tended to pollute more. This hints at the kind of strategies of distraction and deception that many see as endemic and even constitutive of post-modern "managerial" behaviour. Eventually, a price will be paid. For these reasons, the authors recommend that the nascent ISO 26000 (social performance) should now be "designed as a guidance standard", that is, without certification. Proponents of CSR should try to work actively (i.e. "act good") to encourage more authentic CSR initiatives by corporate managers.

If the role of ex post performance indicators is eventually going to be downplayed, because they are manipulative and malleable, what else can be done to bring about authentic ethical business behavior, in the future? The answer, according to the CEO of the Council for Socially Responsible Investment (CSRI) in New Zealand, is to focus attention upon ex ante financial and strategic investment decisions. According to Dr. Robert Howell, whose main concern is the ethics and politics of climate change, "a rapid shift... 
of public and private investment into a SRI framework is required, if the World is to avoid dangerous global warming". That conclusion has already been drawn by many climate scientists (e.g. [5]). Currently, it appears that "SRI ... is in single percentage figures only" whilst "there are no successful examples of (making)... SRI mainstream by voluntary means". Accordingly, a change of approach is needed. For example, pension funds and insurance companies should take a long term view, whereupon they would surely accept that "they have a role to play in bringing (the SRI-) perspective to governments and the public". Commercial interests, governments and civil society "must work together" on this issue, everywhere.

In the sixth paper, Adela Coman (North University of Baia Mare, Romania) discusses two of the processes that enable future change: education and entrepreneurship. Following others, she invites us to imagine that we have (all) been educated to "rationalize consumption" and to reduce waste: to live in harmony with nature and the community we are a part of. To make this a reality, institutions of higher education should now function as (role-) models of sustainability, with fairness in their social policies and economic interactions. They should be active in the development of sustainable communities. Such practices are plainly in line with Humboldt's (c. 1870) traditional idea of the university as a change agent. Fortunately, there are already many good examples. We also need a new type of entrepreneur. Unfortunately, many courses in "entrepreneurship" in universities are still traditional, emphasizing ways of starting a small business; instead, they should foster transformational entrepreneurship: the type that changes the values of the stakeholders (and the citizen-voters).

Although CSR-related variants of governance, accounting, business education and Capitalism have all been well-documented, even for centuries, one can make the case that a fully ethical business enterprise ought to behave even better than any of the current variants would require. In an editorial contribution (paper 7), Singer investigates the idea that businesses should intentionally promote humane ideals. He makes a case that enterprises themselves, as well as institutions, ought to proactively compensate for each of the known limitation of market-based systems. This is because the latter precisely "limit" or constrain the achievement of humane ideals such as justice, care and rights. In most systems, businesses strategically exploit the limitations, rather than deliberately compensate for them.
Singer claims that the idea of "compensatory strategy" (and the Humans-Ideals-Management variant of Capitalism that it would generate, if legislated and fostered), is not an ideology. It merely expresses an accurate understanding of markets, a rational belief in the general effectiveness of good intentions by powerful competent actors, as well as an appeal to widelyheld intuitions about fairness in society. The paper also shows how the set of known limitations yield a useful basis for systematically comparing and contrasting all "variants" of capitalism.

In the final paper of the issue, Miguel Alzola (Rutgers) also explores forms of compensation. He asks whether "multinationals should discharge the duties that correlate with welfare human rights" and like others (e.g. [6]) he gives consideration to when, or under what circumstances, MNCs should respond to the "growing social expectations" that they aid the deprived, or act as agents-of-justice. Alzola has identified four normative principles to guide the inquiry: membership (of community), ability (to avoid inflicting harm), contribution and fair-play. Under the last two, an agent who has contributed to harm becomes responsible for compensation; whilst an agent who has accepted benefits is also called upon to compensate.

According to Alzola, the identification of the dutybearer (the moral agent) in any particular case depends upon the relevant "scenario-of-justice". These can be classified according to the degree of urgency: low vs. high, as well as the political context: ideal vs. nonideal. (In an ideal context, the state is acting as the primary agent of justice.)

Alzola's proposed "Principle of Fair Play" has wide implications for CSR and ethics in the international context. Throughout history, severe deprivations of human rights have occurred during historical episodes that have, directly or indirectly, created conditions receptive to foreign direct investment. ${ }^{3}$ These conditions have, to put it mildly, benefited MNCs as a class, and have been tacitly accepted by them. Accordingly every MNC and arguably every stakeholder, government, enterprise and citizen who has benefited would be called upon to provide some compensation. While about $50 \%$ of readers might find this ridiculous, it is a fair bet that practicing business managers who are genuine about their social responsibility would not only agree, but would already be "acting good" in this way.

\footnotetext{
${ }^{3}$ Pilger [9] and Klein [3] have written in detail and forcefully about a possible direct causal link between those deprivations and the creation of conditions receptive to FDI.
} 


\section{References}

[1] K. Goodpaster, Ethical frameworks for management, in: Policies \& Persons, J.B. Mathews, K. Goodpaster and L. Nash, eds, McGraw Hill, NY, 1985.

[2] A.A. King and M.J. Lenox, Industry self-regulation without sanctions: The chemical industry's responsible care program, Academy of Management Journal 43(4) (2000), 698.

[3] N. Klein, The Shock Doctrine: The Rise of Disaster Capitalism, Metropolitan Books, 2007.

[4] F.H. Knight, The Ethics of Competition, Unwin, Woking, 1936.

[5] M. Lynas, Six Degrees, NationalGeographic.com, 2006.
[6] J. Margolis and P. Walsh, Misery loves companies: rethinking social initiatives by business, Administrative Science Quarterly 48(2) (2003), 268-306.

[7] M.A. O'Conner, Comment on Bassi et al., in: The New Relationship: Human Capital and the American Corporation, M.M. Blair and T.A. Kochan, eds, Brookings Institute Press, Washington, DC, 2000.

[8] M. Oral, An industrial competitiveness model, IIE Transactions 18(2) (1986), 148-157.

[9] J. Pilger, Hidden Agendas, New Press, 1999.

[10] M. Zeleny, Human Systems Management: Integrating Knowledge Management and Systems, World Scientific, Singapore, 2005. 